\title{
Microstructure and Mechanical Properties of the Cold-Rolled Mg-14Li-1Zn Alloy after Hot Rolling
}

\author{
Qiang Wu, ${ }^{1,2}$ Kunning Fu, ${ }^{1}$ Ruizhi Wu $\mathbb{D}^{1,3}$ Jinghuai Zhang, ${ }^{1}$ Legan Hou, ${ }^{1}$ \\ and Milin Zhang ${ }^{1,3}$ \\ ${ }^{1}$ Key Laboratory of Superlight Materials \& Surface Technology, Ministry of Education, Harbin Engineering University, \\ Harbin 150001, China \\ ${ }^{2}$ Harbin Kedewei Metallurgy Co., Ltd., Harbin 150078, China \\ ${ }^{3}$ College of Science, Heihe University, Heihe 164300, China
}

Correspondence should be addressed to Ruizhi Wu; rzwu@hrbeu.edu.cn

Received 10 September 2019; Revised 26 October 2019; Accepted 1 November 2019; Published 25 November 2019

Academic Editor: Pavel Lejcek

Copyright (c) 2019 Qiang Wu et al. This is an open access article distributed under the Creative Commons Attribution License, which permits unrestricted use, distribution, and reproduction in any medium, provided the original work is properly cited.

The as-cast Mg-14Li-1Zn alloy was hot rolled at different temperatures with the reduction of $50 \%$, followed by cold rolling with the reduction of $80 \%$. The effects of the hot rolling temperature on the microstructure and mechanical properties of the final specimens were investigated. The results show that the higher rolling temperature brings about a more homogeneous microstructure, which is favorable for the subsequent cold rolling. When the hot rolling temperature is $300^{\circ} \mathrm{C}$, the final specimen possesses the highest tensile strength and hardness of $238 \mathrm{MPa}$ and $67.7 \mathrm{HV}$, respectively. When the hot rolling temperature is $200^{\circ} \mathrm{C}$, the final specimen possesses the highest elongation of $24.6 \%$.

\section{Introduction}

Mg-Li base alloys have been attracting more and more attention from researchers. The existence of Li element causes a low density of the alloys, $1.35-1.65 \mathrm{~g} / \mathrm{cm}^{3}$, which is very appealing for the application in the fields of aerospace and weapon equipment. Additionally, the addition of $\mathrm{Li}$ into $\mathrm{Mg}$ brings about a good plasticity due to the reduction of c/a value of $\alpha(\mathrm{Mg})$ crystal lattice and the introduction of bodycentered cubic (BCC) phase of $\beta(\mathrm{Li})$ [1].

With the requirement of light-weight becoming more and more harsh, the Mg-Li alloy with high Li content becomes more and more welcome in the material design. When Li content is larger than $10.3 \mathrm{wt} . \%$, the matrix of the $\mathrm{Mg}-\mathrm{Li}$ alloy is a single phase with the BCC structure [2]. The single-phase Mg-Li alloys with the BCC structure always possess a relatively low strength. Fortunately, they possess good plasticity, which provides a large potential for strengthening through deformation. Accordingly, it is a good strategy to obtain an alloy with high specific strength through deforming high Li content Mg-Li alloys [3]. Because of the different crystal structure of BCC from HCP, the deformation behavior of high $\mathrm{Li}$ content $\mathrm{Mg}$ - $\mathrm{Li}$ alloys is different from that of ordinary $\mathrm{Mg}$ alloys $[4,5]$. Therefore, it is necessary to investigate the effects of deformation processing on the microstructure and mechanical properties of $\mathrm{Mg}-\mathrm{Li}$ alloys with high $\mathrm{Li}$ content.

In our previous literature [6], considering the excellent plasticity of the Mg-14Li-1Zn alloy, the alloy was cold rolled directly with the purpose to obtain strain strengthening as large as possible. The ultimate tensile strength is improved from $117 \mathrm{MPa}$ to $210 \mathrm{MPa}$ with a rolling reduction of larger than $70 \%$. But, most of the specimens possess poor elongation, lower than $10 \%$. It was found that the poor elongation was attributed to the inhomogeneous microstructure during cold rolling.

In the previous literatures [6-8], the high Li content Mg$\mathrm{Li}$ alloys were rolled at either elevated or room temperature. In summary, the strengthening effect of hot rolling on the alloys is limited, but the alloys keep good plasticity. On the contrary, the cold rolling has an obvious strengthening effect, but the plasticity of the alloys is poor. Accordingly, the 


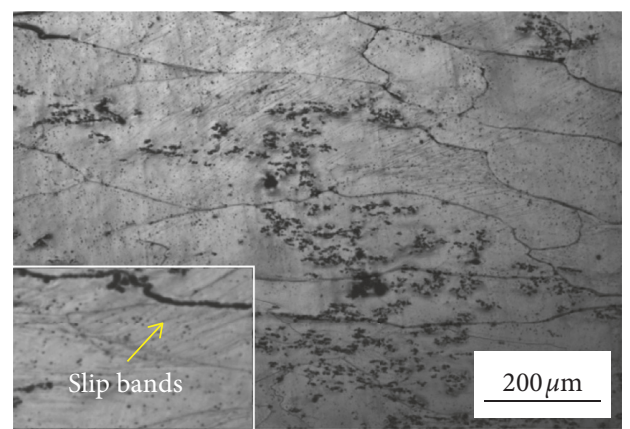

(a)

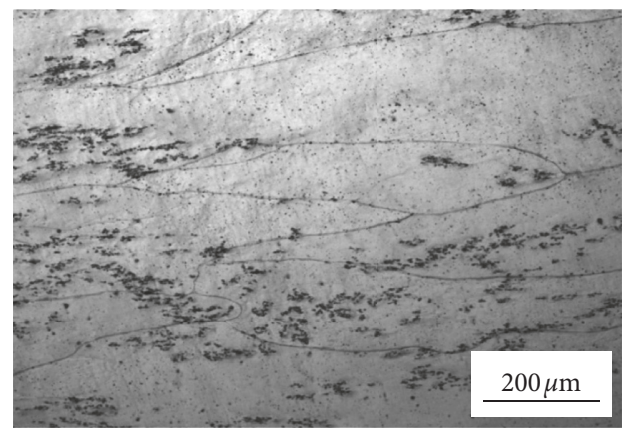

(c)

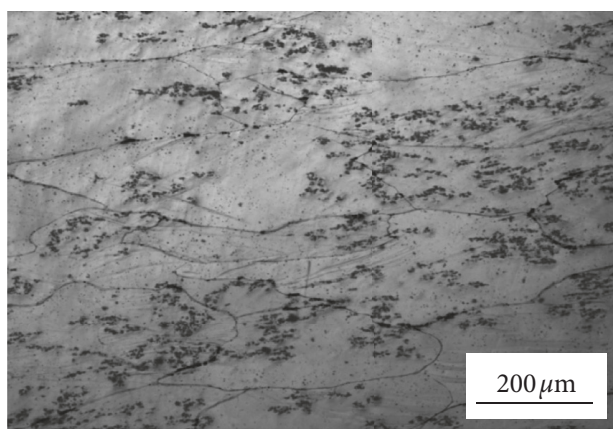

(b)

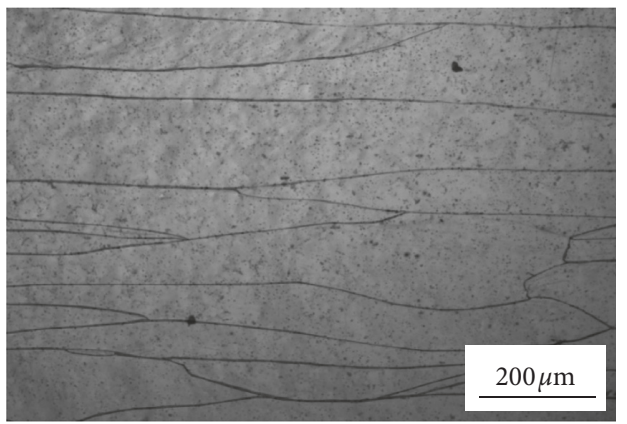

(d)

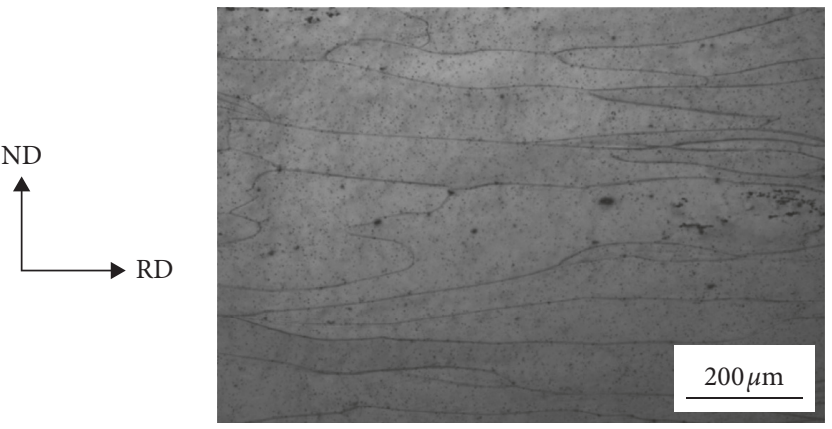

(e)

Figure 1: OM images of the hot-rolled specimen under different temperatures. (a) $100^{\circ} \mathrm{C}$; (b) $150^{\circ} \mathrm{C}$; (c) $200^{\circ} \mathrm{C}$; (d) $250^{\circ} \mathrm{C}$; (e) $300^{\circ} \mathrm{C}$.

combination of the advantages of both cold rolling and hot rolling is appealing for improvements of both strength and plasticity.

In this paper, the strategy is to combine the advantages of both cold rolling and hot rolling, so as to obtain the high $\mathrm{Li}$ content Mg-Li alloys with good comprehensive mechanical properties. A process of hot rolling was carried out before cold rolling. The effects of the hot rolling on the microstructure and mechanical properties of the final cold-rolled Mg-14Li-1Zn alloy were investigated.

\section{Materials and Methods}

A high Li content of the Mg-Li alloy, Mg-14Li-1Zn, was prepared from commercial pure metals of $\mathrm{Mg}, \mathrm{Li}$, and $\mathrm{Zn}$. The ingots of $\mathrm{Mg}, \mathrm{Li}$, and $\mathrm{Zn}$ were loaded in a graphite crucible which was mounted in the furnace chamber. The chamber was pumped into vacuum, and then the chamber was filled with the inert argon atmosphere. Subsequently, the heating process began and the ingots in the crucible were heated to $700^{\circ} \mathrm{C}$ and the temperature was held for $15 \mathrm{~min}$. Then, the melt was poured into a permanent mold to obtain a book-shape as-cast alloy. The as-cast alloy was homogenized at $200^{\circ} \mathrm{C}$ for $12 \mathrm{~h}$. Then, the specimens were hot rolled at $150-300^{\circ} \mathrm{C}$ with a rolling reduction of $50 \%$. Finally, the hot-rolled specimens were further cold rolled with a rolling reduction of $80 \%$.

The microstructure of the specimen was observed with optical microscopy (OM) and transmission electron microscopy (TEM). The specimen for OM is mechanically polished and then is etched with 3 vol. $\%$ nital. The fracture microstructure was observed with scanning electron microscopy (SEM).

The hardness of the alloy was measured with a microhardness tester. The loading force was $100 \mathrm{gf}$, and the holding time is $15 \mathrm{~s}$. The tensile test was conducted with an initial strain rate of $1 \times 10^{-3} \mathrm{~s}^{-1}$. The gauge dimensions of the tensile specimens were $16 \mathrm{~mm} \times 4 \mathrm{~mm} \times 2 \mathrm{~mm}$. 


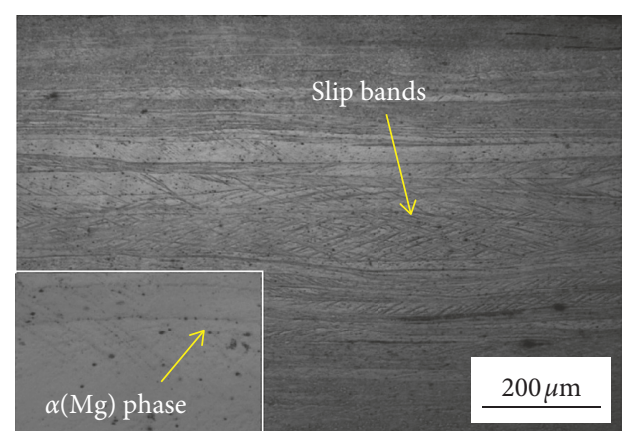

(a)

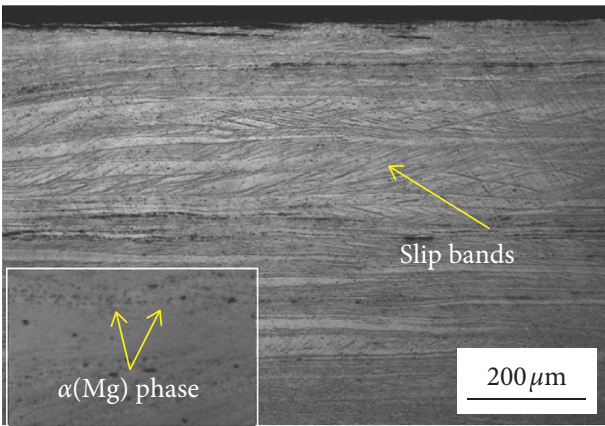

(c)

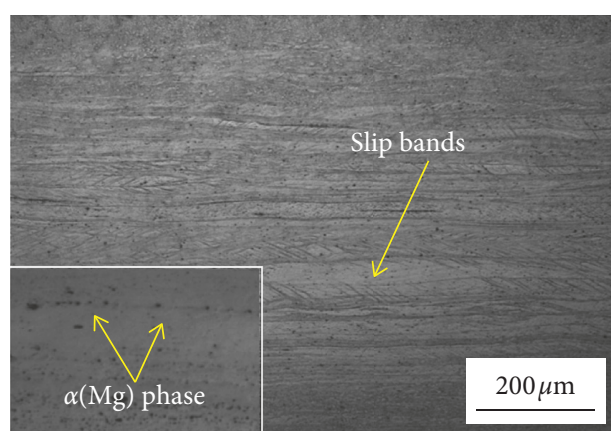

(b)

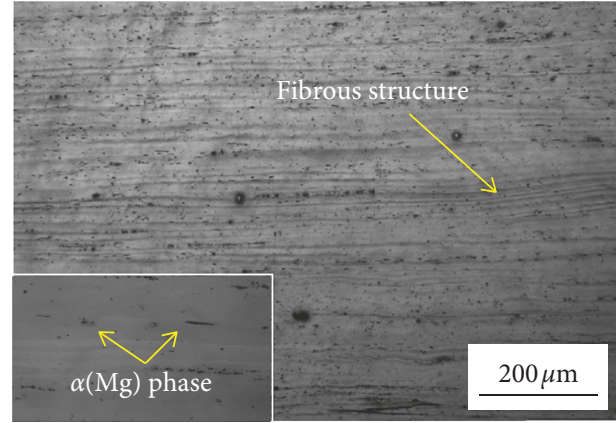

(d)

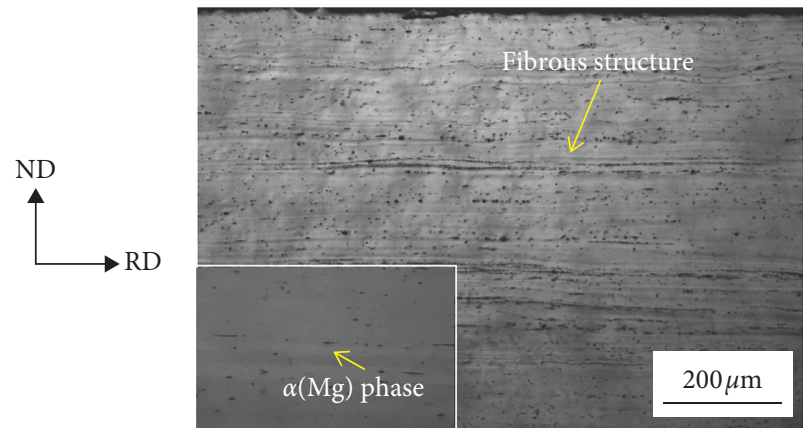

(e)

Figure 2: OM images of the cold-rolled specimen after hot rolling under different temperatures. (a) $100^{\circ} \mathrm{C}$; (b) $150^{\circ} \mathrm{C}$; (c) $200^{\circ} \mathrm{C}$; (d) $250^{\circ} \mathrm{C}$; (e) $300^{\circ} \mathrm{C}$.

\section{Results and Discussion}

The microstructure of the as-cast $\mathrm{Mg}-14 \mathrm{Li}-1 \mathrm{Zn}$ alloy has been reported in our previous literature [6]. It is known that the matrix of the alloys is $\beta(\mathrm{Li})$, in which a minute quantity of spherical $\alpha(\mathrm{Mg})$ distribute. Grains of the as-cast alloy are inhomogeneous and coarse with an average grain size of $300-800 \mu \mathrm{m}$. Accordingly, here we only provide the microstructure of hot-rolled and the subsequent cold-rolled specimens.

3.1. Microstructure of the Hot-Rolled Mg-14Li-1Zn Alloy. The OM images of the Mg-14Li-1Zn alloy hot rolled at different temperatures with the rolling reduction of $50 \%$ are shown in Figure 1 . At $100^{\circ} \mathrm{C}$, the grains are elongated and many slip bands exist along $45^{\circ}$ with the rolling direction. With the increase of rolling temperature, the grains are deformed as an elongated shape more seriously, and the amount of slip bands becomes less. The deformation of the grains becomes more homogeneous.

3.2. Microstructure of the Cold-Rolled Mg-14Li-1Zn Alloy. Figure 2 shows the OM images of the cold-rolled specimens after hot rolling at different temperatures. When the temperature of hot rolling process is low, the microstructure is inhomogeneous with the serious deformed structure near the surface and the slip bands at the center of the sheets, displaying a layered microstructure. With the increase of temperature, the microstructure becomes more and more homogeneous. When the hot rolling temperature is $200^{\circ} \mathrm{C}$, the slip bands evenly distribute, as exhibited in Figure 2(c). When the temperature is higher than $250^{\circ} \mathrm{C}$, the fibrous structure becomes obvious, as shown in Figures $2(\mathrm{~d})$ and 2(e).

Figure 3 illustrates the TEM images of the cold-rolled Mg$14 \mathrm{Li}-1 \mathrm{Zn}$ alloy after hot rolling at different temperatures. 


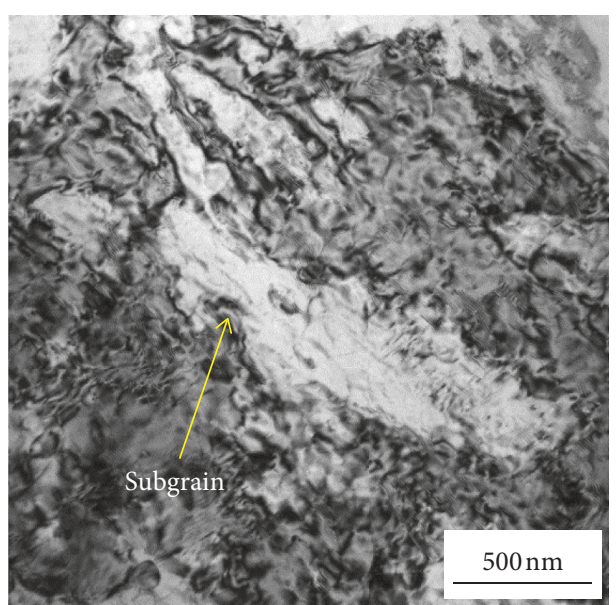

(a)

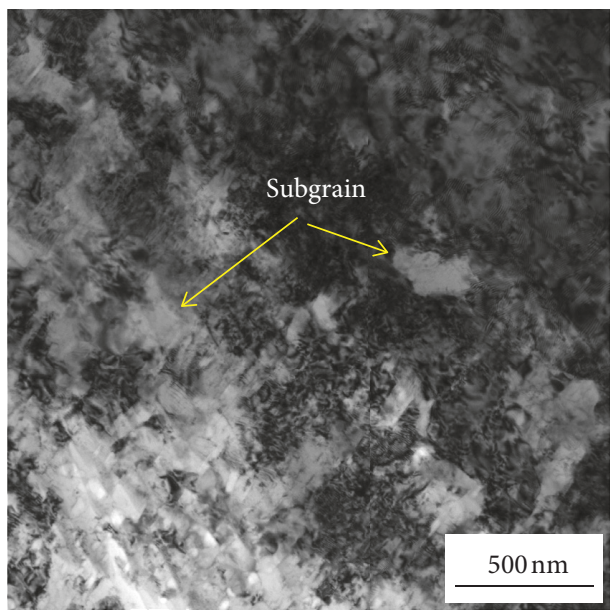

(c)

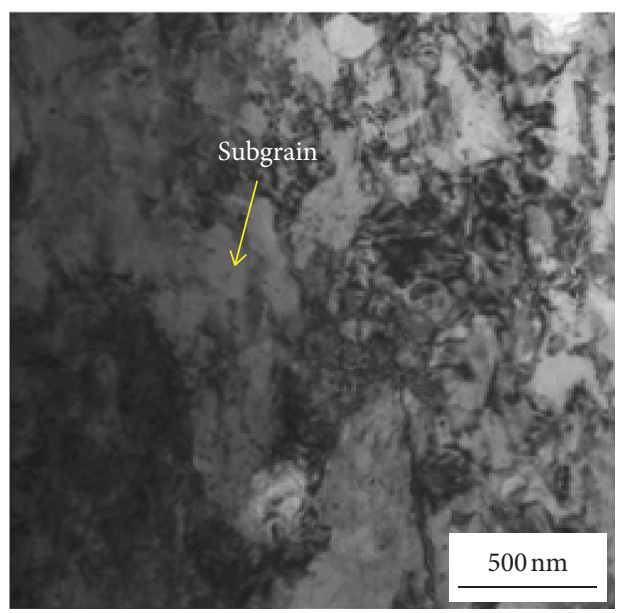

(e)

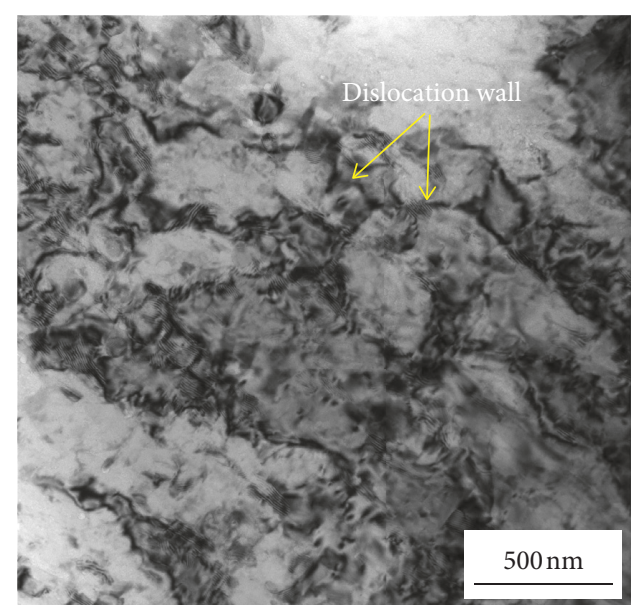

(b)

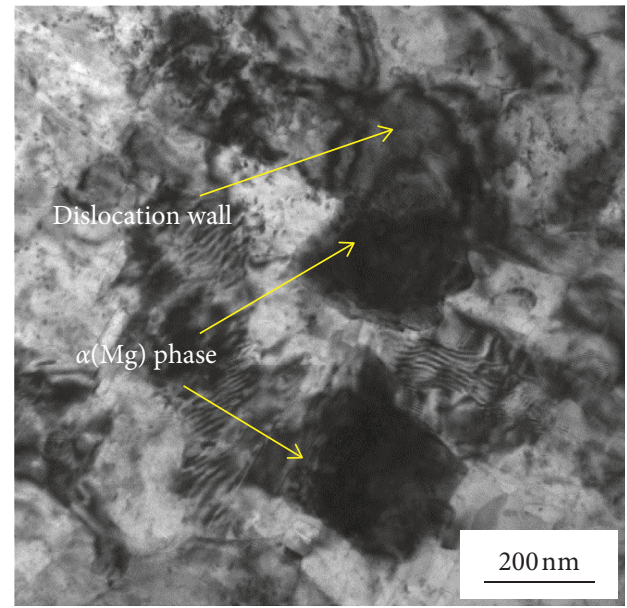

(d)

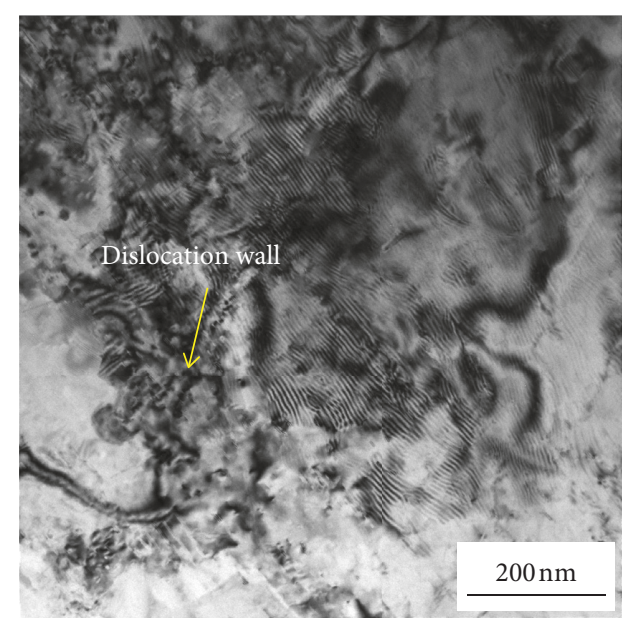

(f)

Figure 3: Continued. 


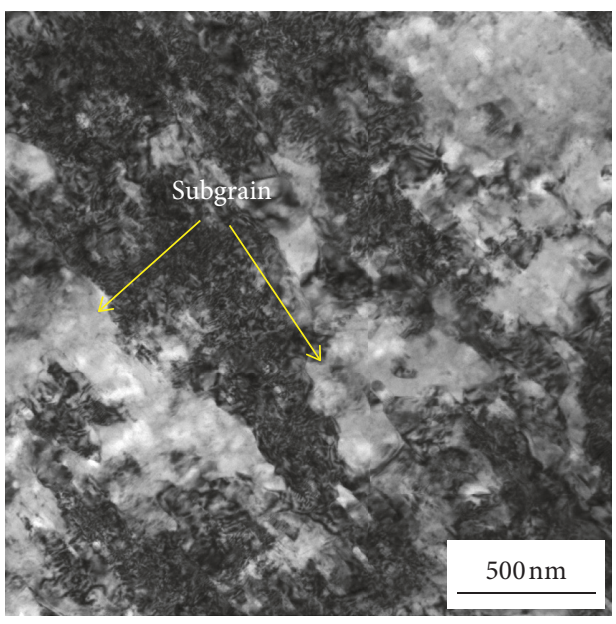

(g)

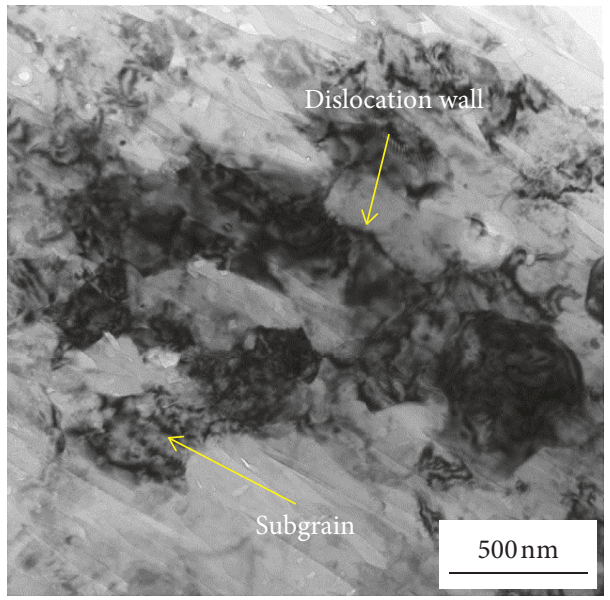

(i)

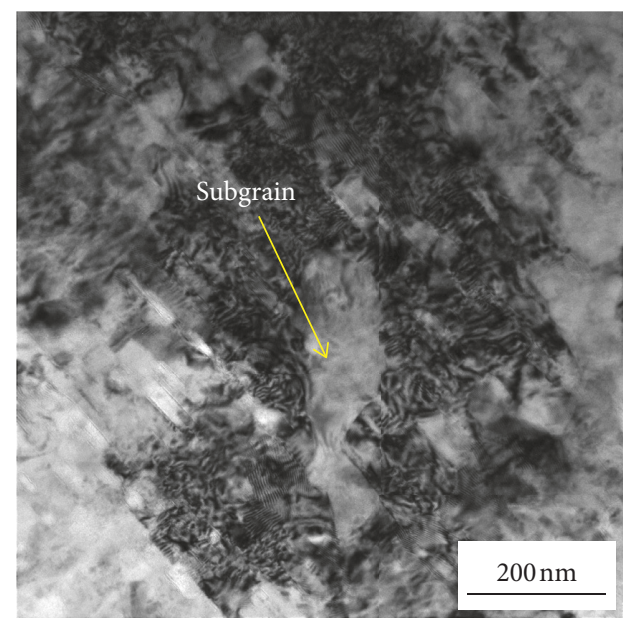

(h)

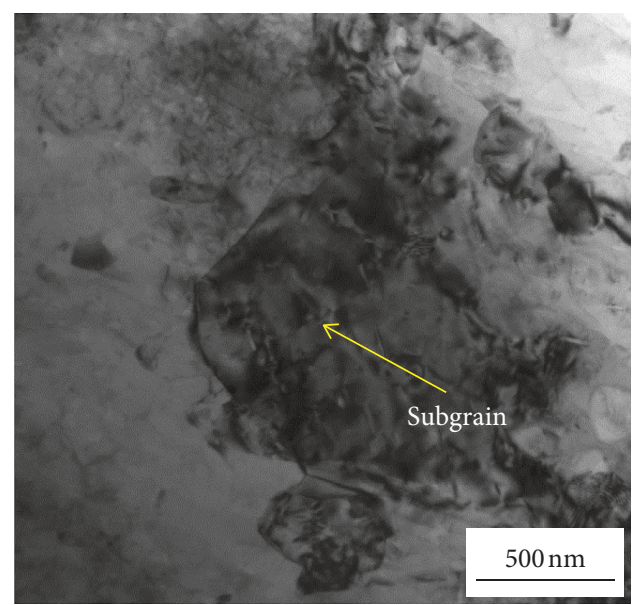

(j)

FIGURE 3: TEM images of the cold-rolled specimen after hot rolling under different temperatures. (a, b) $100^{\circ} \mathrm{C}$; (c, d) $150^{\circ} \mathrm{C}$; (e, f) $200^{\circ} \mathrm{C}$; (g, h) $250^{\circ} \mathrm{C} ;(\mathrm{i}, \mathrm{j}) 300^{\circ} \mathrm{C}$.

From Figures 3(a) and 3(b), many subgrains with the size of $500-1000 \mathrm{~nm}$ exist in the alloy under $100^{\circ} \mathrm{C}$. The broad span of size distribution is caused by the inhomogeneous microstructure because of the low temperature during hot rolling [9]. The disorientation cannot be eliminated during hot rolling at low temperature, which triggers the abnormal growth of subgrains. When the temperature is $150^{\circ} \mathrm{C}$, many dislocations pile-up, and a small amount of subgrains with a size of $200 \mathrm{~nm}$ exist among the dislocations, which demonstrates that the dynamic recovery occurs through polygonization. It can also be observed that, when the head dislocation moves through granular $\alpha(\mathrm{Mg})$, the dislocation bends because of the restrain caused by the antiphase boundary. Accordingly, the interaction between dislocations and $\alpha(\mathrm{Mg})$ brings about the Orowan strengthening [10]. From Figures 3(e) and 3(f), a large amount of subgrains form with a narrower size span compared to that of Figures 3(c) and $3(\mathrm{~d})$, and they distribute more evenly. After hot rolling at $250^{\circ} \mathrm{C}$, the amount of subgrains becomes less and these subgrains distribute evenly. It can be concluded that during the cold rolling, the deformation happens evenly and the strain-softening mechanism becomes weaker, and the dislocations can be effectively piled up [11]. The microstructure in Figures 3(i) and 3(j) is very different from that at other temperatures. The dislocation pile-up exists in the subgrains, not around the subgrains. It can be inferred that the subgrains form during the hot rolling at $300^{\circ} \mathrm{C}$, and during the subsequent cold rolling, the sheet is deformed uniformly without dynamic recovery because of the less amount of dislocations in the state of hot rolling. During the subsequent cold rolling, the dislocations form in the subgrains, causing the strain hardening obviously [12].

In summary, the hot rolling temperature has obvious influence on the microstructure of the subsequent cold rolling specimens. If the microstructure of hot rolling is homogeneous with a low density of dislocations, it is favorable for the dislocation pile-up during the subsequent cold rolling.

3.3. Hardness. Figure 4 shows the hardness of the specimens after hot rolling with $50 \%$ reduction (50\% HR) and hot rolling plus cold rolling with $50 \%$ reduction and $80 \%$ reduction $(50 \% \mathrm{HR}+80 \% \mathrm{CR})$, respectively. It can be observed 


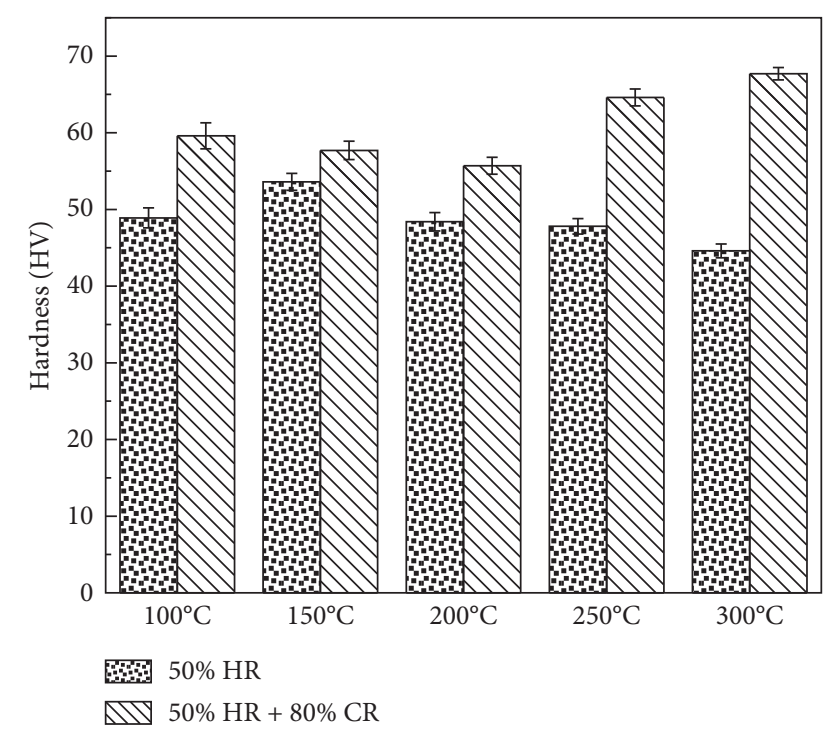

FIgURE 4: Hardness values of the specimens after hot rolling and hot rolling plus cold rolling.

that the subsequent cold rolling improves the hardness of the hot-rolled specimens. As for the specimens with the temperature lower than $200^{\circ} \mathrm{C}$, the increase of hardness caused by cold rolling is not obvious. When the temperature is larger than $200^{\circ} \mathrm{C}$, the increase of hardness is obvious.

When the hot rolling temperature is low, the hardness of the hot-rolled specimen is relatively higher than that of high temperature because of the large amount of dislocations formed during hot rolling. In the subsequent cold rolling, the dislocations can trigger the process of dynamic recovery, and the work hardening happens simultaneously. Under the comprehensive effects of dynamic recovery and work hardening, the unobvious improvement of hardening is obtained [13]. Under the temperature higher than $200^{\circ} \mathrm{C}$, the hot-rolled microstructure is homogeneous with a low density of dislocations, and many subgrains exist in the microstructure. In the subsequent process of cold rolling, many dislocations form in the subgrains, causing the increases of dislocation density. Accordingly, the obvious increase of hardness is obtained [14].

3.4. Tensile Testing Properties. Figure 5 shows the stressstrain curves of the hot-rolling plus cold-rolling specimens under different temperatures, and the strength and elongation values are listed in Table 1 . When the temperature is $100^{\circ} \mathrm{C}$, the tensile strength and elongation are both the lowest, $179 \mathrm{MPa}$ and $11.9 \%$, respectively. From the OM images, the hot-rolled microstructure under this temperature is not homogeneous with obvious plastic deformation at the surface of the sheet and the almost undeformed microstructure at the center of the sheet. Under this state, some microcracks will exist inevitablely during the subsequent cold rolling, causing the poor strength and elongation [15]. The specimen under $200^{\circ} \mathrm{C}$ possesses the highest elongation of $24.6 \%$. This can be attributed to the dynamic recovery and subgrains. The specimen under $300^{\circ} \mathrm{C}$ possesses the highest

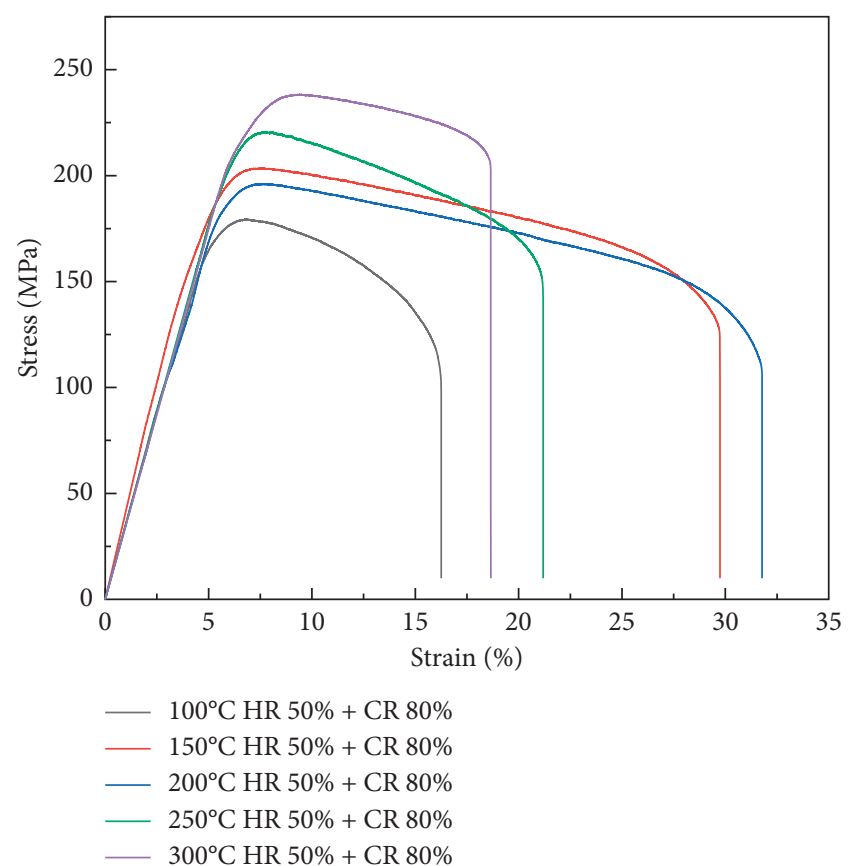

FIGURE 5: The stress-strain curves of the hot-rolling plus coldrolling specimens under different temperatures.

TABLe 1: Tensile testing values from Figure 5.

\begin{tabular}{lcc}
\hline $\begin{array}{l}\text { Temperature } \\
\left({ }^{\circ} \mathrm{C}\right)\end{array}$ & $\begin{array}{c}\text { Ultimate tensile } \\
\text { strength } \\
(\mathrm{MPa})\end{array}$ & $\begin{array}{c}\text { Elongation } \\
(\%)\end{array}$ \\
\hline 100 & 179 & 11.9 \\
150 & 204 & 22.9 \\
200 & 196 & 24.6 \\
250 & 220 & 16.3 \\
300 & 238 & 14.2 \\
\hline
\end{tabular}

strength of $238 \mathrm{MPa}$. The grain disorientation is weakened and a homogeneous microstructure is obtained. The hotrolled microstructure is favorable for the homogeneous plastic deformation. A large amount of dislocations exist in the cold-rolled sheet, causing a high strength [16].

\section{Conclusions}

(1) The microstructure of the hot-rolled specimen becomes more and more homogenous with the increase of rolling temperature.

(2) The homogenous hot-rolled microstructure is favorable for the subsequent cold rolling, which brings about the improved mechanical properties.

(3) The specimen under the rolling temperature of $300^{\circ} \mathrm{C}$ possesses the highest tensile strength and hardness, $238 \mathrm{MPa}$ and $67.7 \mathrm{HV}$, respectively. The specimen under the temperature of $200^{\circ} \mathrm{C}$ possesses the highest elongation of $24.6 \%$.

\section{Data Availability}

All the data used to support the findings of this study are included within the article and are available from the 
corresponding author upon request. Previously reported ascast microstructures of the $\mathrm{Mg}-14 \mathrm{Li}-1 \mathrm{Zn}$ alloy were used to support this study and are available at [6]. These prior studies are cited at relevant places within the text as references [8].

\section{Conflicts of Interest}

The authors declare that there are no conflicts of interest regarding the publication of this paper.

\section{Acknowledgments}

This research was funded by the National Natural Science Foundation of China (51671063, 51771060, and 51871068), the Heilongjiang Province Natural Science Foundation (ZD2017010), the Fundamental Research Funds for the Central Universities (HEUCFG201834), and the Harbin City Application Technology Research and Development Project (2017RAQXJ032).

\section{References}

[1] R. Wu, Y. Yan, G. Wang et al., "Recent progress in magnesium-lithium alloys," International Materials Reviews, vol. 60, no. 2, pp. 65-100, 2015.

[2] W. Gasior, Z. Moser, W. Zakulski, and G. Schwitzgebel, "Thermodynamic studies and the phase diagram of the Li-Mg system," Metallurgical and Materials Transactions A, vol. 27, no. 9, pp. 2419-2428, 1996.

[3] V. Kumar, R. Govind, R. Shekhar, R. Balasubramaniam, and K. Balani, "Microstructure evolution and texture development in thermomechanically processed Mg-Li-Al based alloys," Materials Science and Engineering: A, vol. 547, pp. 38-50, 2012.

[4] Y. Sun, R. Wang, J. Ren et al., "Microstructure, texture, and mechanical properties of as-extruded Mg-xLi-3Al-2Zn- $0.2 \mathrm{Zr}$ alloys ( $x=5,7,8,9,11$ wt.\%)," Materials Science \& Engineering A, vol. 755, pp. 201-210, 2019.

[5] J. Zhang, S. Liu, R. Wu, L. Hou, and M. Zhang, "Recent developments in high-strength Mg-RE-based alloys: focusing on Mg-Gd and Mg-Y systems," Journal of Magnesium and Alloys, vol. 6, no. 3, pp. 277-291, 2018.

[6] K. N. Fu, J. H. Wang, M. Qiu et al., "Effects of cold rolling on microstructural evolution and mechanical properties of $\mathrm{Mg}$ 14Li-1Zn alloy," Advanced Engineering Materials, vol. 21, Article ID 1801344, 2019.

[7] Y. Tang, Q. Le, W. Jia, X. Liu, and J. Cui, "Influences of warm rolling and annealing processes on microstructure and mechanical properties of three parent structures containing $\mathrm{Mg}$ Li alloys," Materials Science and Engineering: A, vol. 711, pp. 1-11, 2018.

[8] S. K. Wu, J. Y. Wang, K. C. Lin, and H. Y. Bor, "Effects of cold rolling and solid solution treatments on mechanical properties of $\beta$-phase Mg-14.3Li-0.8Zn alloy," Materials Science and Engineering: A, vol. 552, pp. 76-80, 2012.

[9] W.-H. Liu, X. Liu, C.-P. Tang, W. Yao, Y. Xiao, and X.-H. Liu, "Microstructure and texture evolution in LZ91 magnesium alloy during cold rolling," Journal of Magnesium and Alloys, vol. 6, no. 1, pp. 77-82, 2018.

[10] Z. X. Kang, K. Lin, and J. Y. Zhang, "Characterisation of Mg-Li alloy processed by solution treatment and large strain rolling,"
Materials Science and Technology, vol. 32, no. 5, pp. 498-506, 2016.

[11] G. Liu, W. Xie, G. B. Wei et al., "Dynamic recrystallization behavior and corrosion resistance of a dual-phase $\mathrm{Mg}-\mathrm{Li}$ alloy," Materials, vol. 11, no. 3, Article ID 11030408, 2018.

[12] Y. Tang, Q. Le, R. D. K. Misra, G. Su, and J. Cui, "Influence of extruding temperature and heat treatment process on microstructure and mechanical properties of three structures containing Mg-Li alloy bars," Materials Science and Engineering: $A$, vol. 712, pp. 266-280, 2018.

[13] H. W. Dong, L. M. Wang, K. Liu et al., "Microstructure and deformation behaviors of two Mg-Li dual-phase alloys with an increasing tensile speed," Materials \& Design, vol. 90, pp. 157-164, 2016.

[14] Y. Tang, Q. C. Le, T. Wang et al., "Experimental analysis and mathematical modeling on $\mathrm{Mg}$-Li alloy sheets with three crystal structures during cold rolling and heat treatment," Materials, vol. 10, no. 10, Article ID 10101167, 2017.

[15] C.-T. Chiang, S. Lee, and C.-L. Chu, "Rolling route for refining grains of super light Mg-Li alloys containing Sc and Be," Transactions of Nonferrous Metals Society of China, vol. 20, no. 8, pp. 1374-1379, 2010.

[16] A. Medjahed, M. Derradji, A. Zegaoui, R. Wu, and B. Li, "Processability and mechanical properties of surface-modified glass-fibres/phthalonitrile composite and Al-Li alloy fibremetal-laminates," Materials Science and Technology, vol. 35, no. 6, pp. 661-668, 2019. 


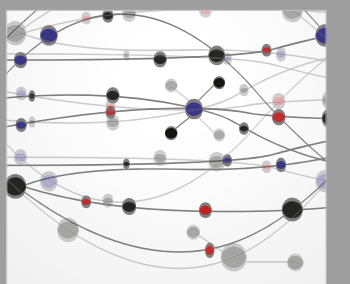

The Scientific World Journal
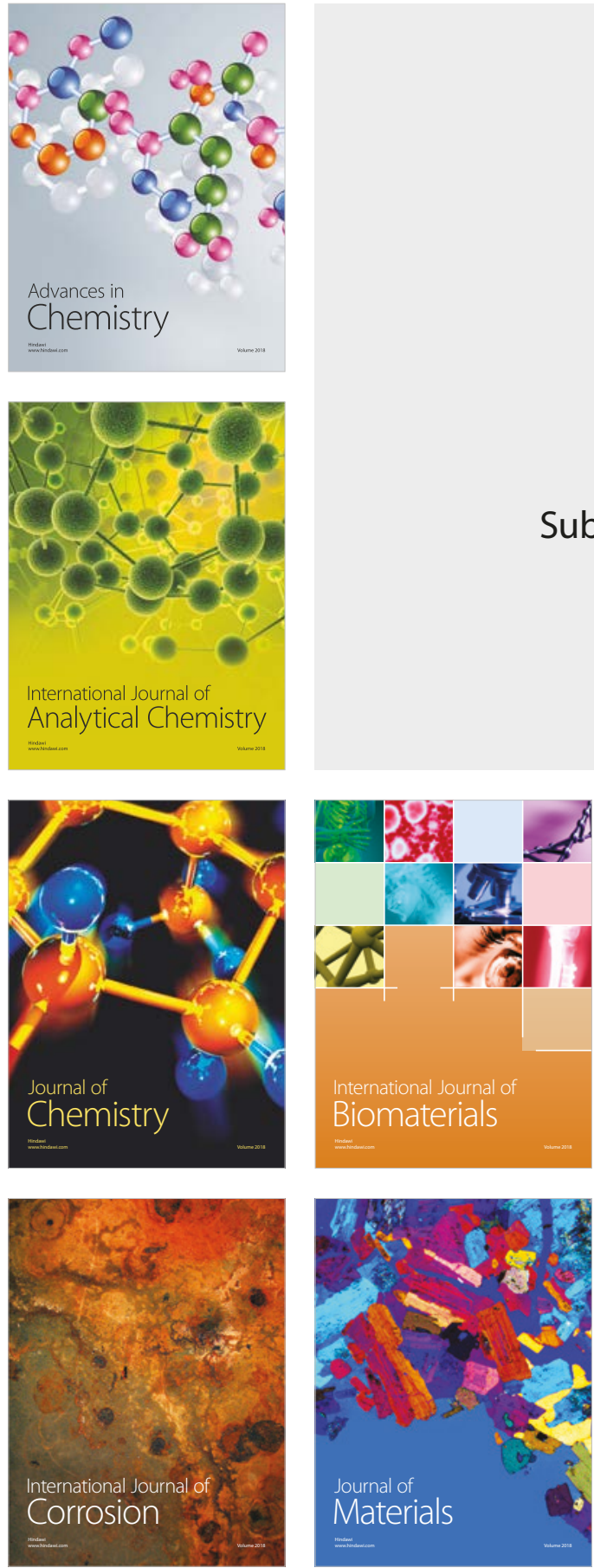

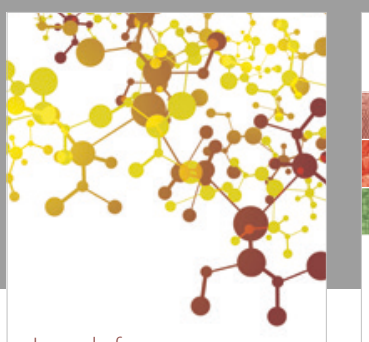

Journal of

Applied Chemistry
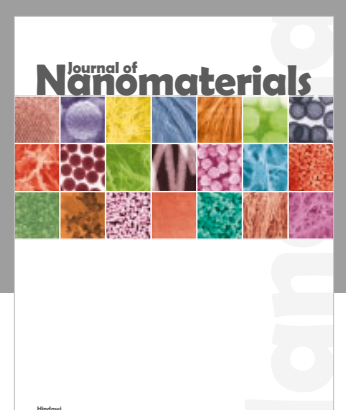

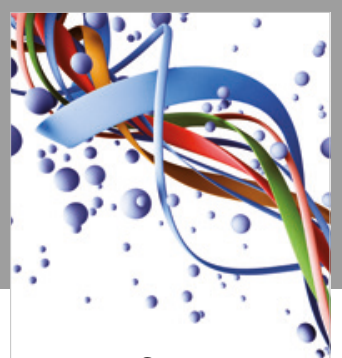

Scientifica

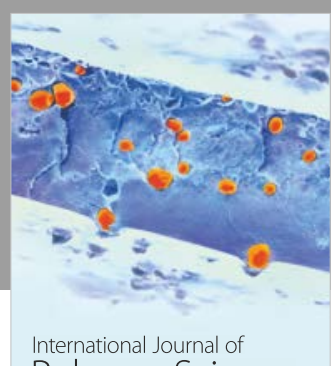

Polymer Science

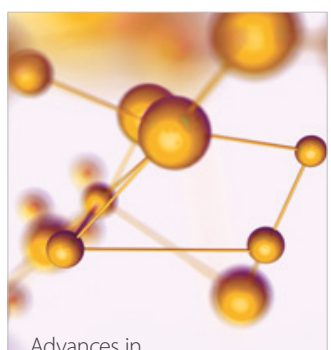

Physical Chemistry
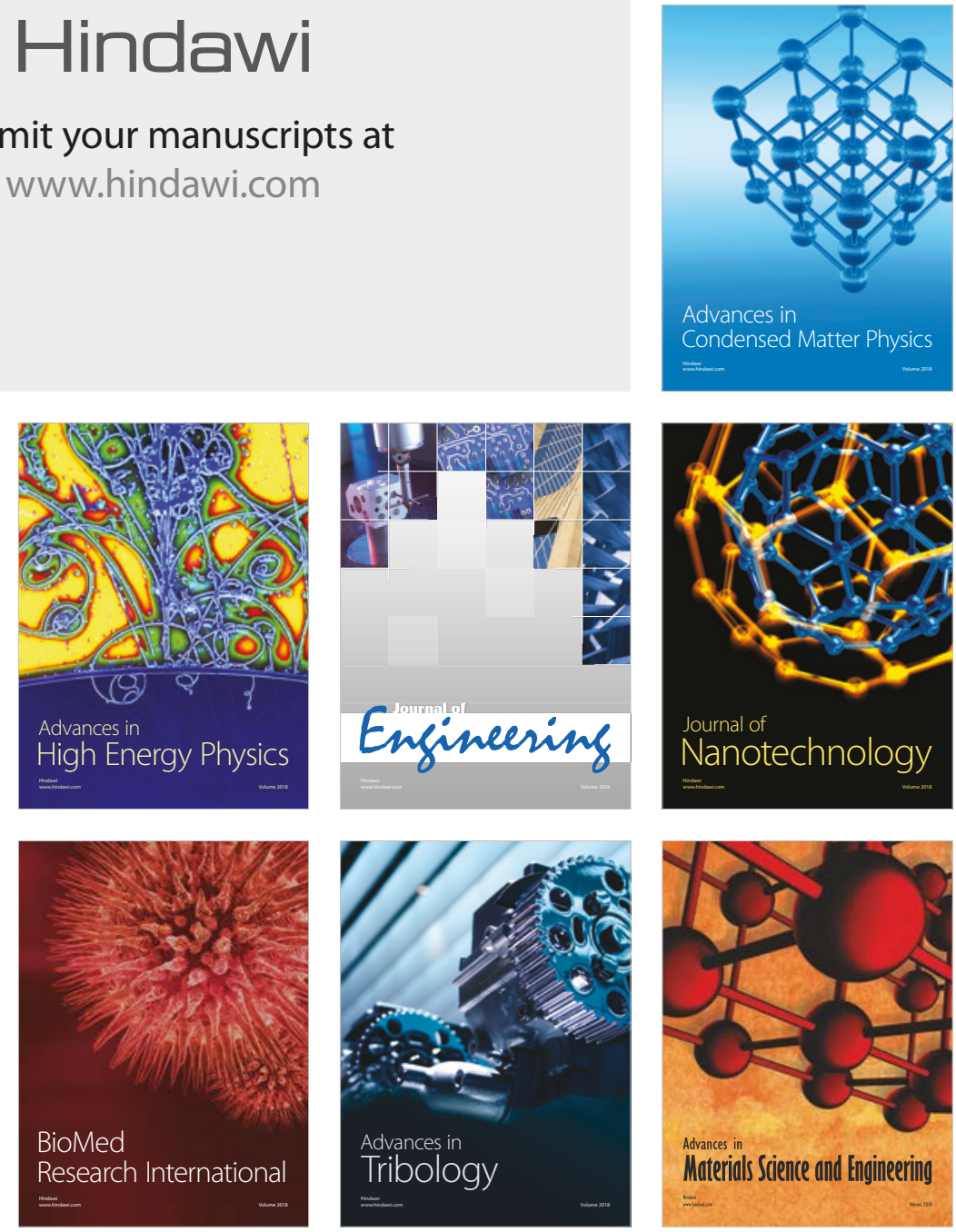